\title{
Crude Oil Measurement Model Based on Artificial Neural Networks
}

\author{
Chen $\mathrm{Bo}^{1, \mathrm{a}}$, Xue Xiaoqing ${ }^{2, \mathrm{~b}}$ Liu Ting $^{3, \mathrm{c}}$ \\ ${ }^{1}$ Physics and Electronic Engineering,Xianyang Normal University, China \\ ${ }^{1}$ Physics and Electronic Engineering,Xianyang Normal University, China \\ ${ }^{1}$ Physics and Electronic Engineering,Xianyang Normal University, China \\ Achen_bo_16@163.coml, b136465361@qq.com, 'whiteliuting@163.com
}

Keywords: neural network, moisture content of crude oil, error compensation, back propagation

\begin{abstract}
ANN technology is being widely used in many fields, Based on the analysis of artificial neural network, a method using multi-sensor in an improved artificial neural network is put forward for the error compensation and control of crude oil measurement model, experimental data are used to verify the result.
\end{abstract}

\section{Introduction}

Artificial Neural Networks (ANN) is defined as a complex network computing system hat composed of large number of highly interconnected simple processing elements: neurons. It is an effective way to imitate artificial intelligence, which can not only be used as a computational model, but also a cognitive model. Currently, back propagation (BP) and radial basis function (RBF) neural network are the most typical feedforward neural network model. Among these, BP neural network is currently the most popular multi-layer feedforward neural network. Since BP neural network has highly self-learning and adaptive ability, generalization ability and nonlinear mapping ability that can approach any nonlinear continuous function with arbitrary precision, so this paper chooses BP neural network as the research object

\section{Error Compensation of Crude Oil Measurement Based on Neural Network}

Through the established multimedia measurement model of crude oil storage tank, it is clear that the moisture content of the oil tank $(\alpha)$ is mainly influenced by many parameters such as the density of water $\left(\rho_{w}\right)$, temperature $(\mathrm{t})$, height $(\mathrm{H})$ and pressure difference $(\Delta P)$. Making the four parameters that affect the moisture content as the input of BP neural network model error compensation the output parameter is the predictive value of error ( $\Delta \alpha$ ) of the actual moisture content of the crude oil.

If the input of a first iteration as input parameters $\rho_{w}, t 、 H 、 \Delta P$ is $x_{i}(k)(i=1,2,3,4)$, the output $\Delta \alpha$ is $y(k), y(k)$ is the actual value relative to $x_{i}(k)$. Squared error of the water content of crude oil is defined as

$$
e(k)=\frac{1}{2}\left[y^{\prime}(k)-y(k)\right]^{2}
$$

If the number is $\mathrm{N}$, then the mean square error is:

$$
E=\frac{1}{N} \sum_{1}^{N} e(k)=\frac{1}{2 N} \sum_{1}^{N}\left[y^{\prime}(k)-y(k)\right]^{2}
$$

The goal of neural network learning is to minimize the constructed objective function. The training steps based on improved simulated annealing algorithm of the neural network are as follows :

(1) initialize the parameters, give values to the network weights( $\left.\omega_{i j}\right)$ and the initial 
temperature $\left(T_{0}\right)$, select the temperature decay function;

(2) calculate the output $(y(k))$ of each training sample $\left(x_{i}(k)\right)$ and the mean square error $\mathrm{E}$;

(3) amend the wight $\left(\omega_{i j}\right)$, assume $\omega_{i j}^{*}=\omega_{i j}+\Delta \omega_{i j}$ is in line with the Cauchy distribution;

(4) through the modified network weight $\left(\omega_{i j}\right)$, recalculat the $\operatorname{output}\left(y^{*}(k)\right)$ with the use of training samples $\left(x_{i}(k)\right)$;

(5) recalculate the mean squared error $E^{*}=\frac{1}{N} \sum_{1}^{N} e(k)=\frac{1}{2 N} \sum_{1}^{N}\left[y^{\prime}(k)-y^{*}(k)\right]^{2}$;

(6) If $E^{*}<E$, make $\omega_{i j}=\omega_{i j}^{*}$; otherwise, accept $\omega_{i j}^{*}$ by the probability $\exp \left(-\Delta E / T_{i}\right)$ calculate the probability $\Delta E=E-E^{*}, T_{i}$ is the current temperature;

(7) Repeat steps three to six, until the mean square error reaches allowable precision

In the process of crude oil measuring, first, use a mathematical model to calculate the water content of crude oil, then draw the predictive value of the moisture content of crude oil with the help of the improved BP neural network to compensate the calculate value of the mathematic model, hence to achieve measurement accuracy and stability of the target, that is:

$$
\alpha=\alpha^{\prime}+\Delta \alpha
$$

$\alpha^{\prime}$ in (5-15) is the calculated value of the mathematical model, $\Delta \alpha$ is the predictive value of the improved artificial neural network, $\alpha$ is the water content of crude oil after error compensation. The system composition of the improved neural network error compensation is shown in Figure.1

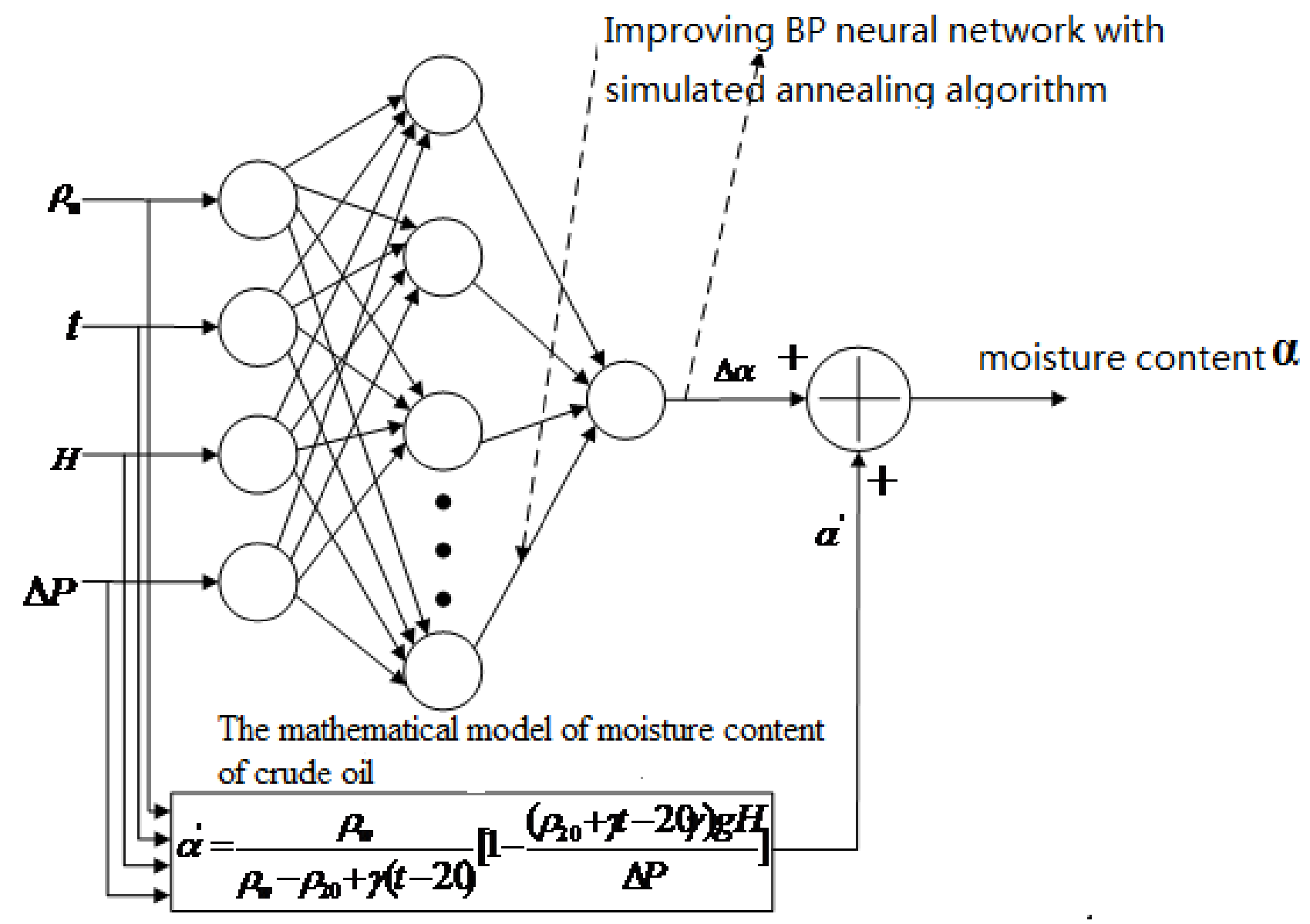

Figure.1 Improved Simulated Annealing BP network error compensation 


\section{Experimental design to get neural network training samples}

In order to use the improved artificial neural network to model and optimize the water content of crude oil, the work to be carried out first is to get the input/output data sample for learning and testing through experimentations. Because the input of neural network generally contains multiple parameters, and functional relationship between the input and output is highly non-linear, so, to obtain input /output data, many times of multifactorial combined experiments must be carried out .

Since orthogonal test has a balanced distribution, less trial numbers, intuitive and easy-to-analyze results, and is easy to analyze the main effects of each factor, So in this article, orthogonal test is used to obtain training samples and test data. Orthogonal experimental design and the results are shown in Table 1.

Table 1 Orthogonal test table of obtaining training samples

\begin{tabular}{|c|c|c|c|c|}
\hline & $\begin{array}{c}\text { volume ratio of } \\
\text { oil - water }\end{array}$ & Temperature & $\begin{array}{l}\text { Error of moisture } \\
\text { content }\end{array}$ & Valid \\
\hline Exp1 & $1(4: 1)$ & $1\left(0^{\circ} \mathrm{C}\right)$ & & \\
\hline Exp2 & $1(4: 1)$ & $2\left(15^{\circ} \mathrm{C}\right)$ & $12.55 \%$ & \\
\hline Exp3 & $1(4: 1)$ & $3\left(23^{\circ} \mathrm{C}\right)$ & $-12.32 \%$ & \\
\hline Exp4 & $2(3: 1)$ & $2\left(15^{\circ} \mathrm{C}\right)$ & $7.25 \%$ & $\sqrt{ }$ \\
\hline Exp5 & $2(3: 1)$ & $3\left(23^{\circ} \mathrm{C}\right)$ & $-6.92 \%$ & $\sqrt{ }$ \\
\hline Exp6 & $2(3: 1)$ & $1\left(0^{\circ} \mathrm{C}\right)$ & & \\
\hline Exp7 & $3(2: 1)$ & $1\left(0^{\circ} \mathrm{C}\right)$ & & \\
\hline Exp8 & $3(2: 1)$ & $2\left(15^{\circ} \mathrm{C}\right)$ & $6.52 \%$ & $\sqrt{ }$ \\
\hline Exp9 & $3(2: 1)$ & $3\left(23^{\circ} \mathrm{C}\right)$ & $-6.34 \%$ & $\sqrt{ }$ \\
\hline Exp10 & $4(1: 2)$ & $3\left(23^{\circ} \mathrm{C}\right)$ & $-5.51 \%$ & $\sqrt{ }$ \\
\hline Exp11 & $4(1: 2)$ & $1\left(0^{\circ} \mathrm{C}\right)$ & & \\
\hline Exp12 & $4(1: 2)$ & $2\left(15^{\circ} \mathrm{C}\right)$ & $5.64 \%$ & $\sqrt{ }$ \\
\hline Exp13 & $5(1: 3)$ & $3\left(23^{\circ} \mathrm{C}\right)$ & $-4.95 \%$ & $\sqrt{ }$ \\
\hline Exp14 & $5(1: 3)$ & $1\left(0^{\circ} \mathrm{C}\right)$ & & \\
\hline Exp15 & $5(1: 3)$ & $2\left(15^{\circ} \mathrm{C}\right)$ & $5.10 \%$ & $\sqrt{ }$ \\
\hline Exp16 & $6(1: 4)$ & $2\left(15^{\circ} \mathrm{C}\right)$ & $4.51 \%$ & $\sqrt{ }$ \\
\hline Exp17 & $6(1: 4)$ & $3\left(23^{\circ} \mathrm{C}\right)$ & $-4.32 \%$ & $\sqrt{ }$ \\
\hline Exp18 & $6(1: 4)$ & $1\left(0^{\circ} \mathrm{C}\right)$ & & \\
\hline
\end{tabular}

Through the table, it could be drawn that when the moisture content is more than $30 \%$, the error range of the moisture content is small, which is helpful for the measurement of moisture content of crude oil. In obtaining the samples, the range of the oil content of more than $70 \%$ should be avoided.

\section{Network sample test}

The improved BP network simulated annealing the samples after training to meet the requirements, the improved $\mathrm{BP}$ network sample need to be tested to see whether the moisture content of the crude oil has reduced and whether the measurement accuracy is improved.To this end, 
here are some of the test data, as shown in Table 2

Table 2 Network sample test data

\begin{tabular}{ccccc}
\hline $\begin{array}{c}\text { Temperatur } \\
\text { e }\end{array}$ & Oil/Water(volume) & $\begin{array}{c}\text { Measured } \\
\text { Moisture } \\
\text { Content }\end{array}$ & $\begin{array}{c}\text { Error } \\
\text { compensation } \\
\text { value of BP } \\
\text { neural network } \\
\text { algorithm }\end{array}$ & $\begin{array}{c}\text { Actual Moisture } \\
\text { Content }\end{array}$ \\
\hline 21 & $4: 6$ & $65.67 \%$ & $63.40 \%$ & $60.00 \%$ \\
21 & $4: 8$ & $71.46 \%$ & $70.25 \%$ & $66.67 \%$ \\
23 & $4: 10$ & $76.50 \%$ & $73.68 \%$ & $71.43 \%$ \\
24 & $4: 12$ & $80.42 \%$ & $77.55 \%$ & $75.00 \%$ \\
\hline
\end{tabular}

Through sample test, measurement error of the moisture content is relatively great: between $5 \%$ $-7 \%$; after improving neural network error compensation, the error range is between $3 \%-4 \%$. Therefore, an improved simulated annealing BP network error compensation, to a certain extent can reduce errors and improve oil measurement accuracy.

\section{Summary}

The text describes the establishment of the crude oil measurement model based on an improved BP network, through orthogonal experimental design, network training sample are obtained and tested, test results show that the error of water content of crude oil has been reduced and the measurement accuracy has been improved comparing with that before error compensation of the improved BP network ,

\section{Acknowledgements}

This article is subsidized by special funded projects of Xianyang Normal University

\section{References}

[1] Dj.M. Maric, PF Meier and SK Estreicher: Mater Sci Forum Vol 83-87 (1992), p 119.

[2] Dong Taijun. Error Analysis and Data Processing [M].Beijing:Tsinghua University Press, 2013: 25-80.

[3] Tian Jingwen, Gao Meijuan. Artificial Neural Network Nesearch and Its Application [M] Beijing: Beijing Institute of Technology Press, 2006: 25-39.

[4] Cao Xianqing, Zhu Jianguang, Tang Ren Yuan. Soft Sensor Technology Based on Improved Algorithm BP Neural Network [J] Journal of Scientific Instrument, 2005,26 (8): 1065-1066.

[5] Chen Chuming, Dai Xiao Mian, Zhang Yonghe and so on. Realization of Simulated Annealing Algorithm in Neural Networks [J] Neural Networks in Modern Computers, 2009 (8): 34-36. 